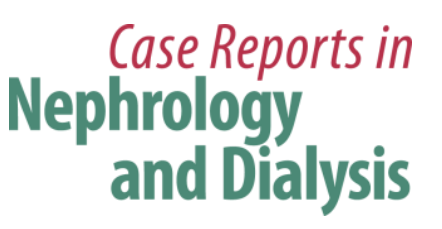

\title{
ANCA-Associated Vasculitis in a Patient with Systematic Sclerosis and Sjögren's Syndrome: A Case Report
}

\author{
Keiichi Kubota $^{a}$ Toshiharu Ueno $^{a}$ Koki Mise $^{a}$ Ryo Hazue \\ Tatsuya Suwabe $^{a} \quad K^{2}$ oichi Kikuchi ${ }^{\text {a }}$ Junichi Hoshino ${ }^{a}$ Keiichi Sumida ${ }^{a}$ \\ Noriko Hayami ${ }^{a}$ Kenmei Takaichi ${ }^{a, c}$ Takeshi Fujii ${ }^{b}$ Kenichi Ohashi ${ }^{b}$ \\ Yoshinori Nonomura ${ }^{d}$ Yosifumi Ubara ${ }^{a, c}$ \\ ${ }^{a}$ Nephrology Center and ${ }^{b}$ Department of Pathology, Toranomon Hospital, \\ cOkinaka Memorial Institute for Medical Research, and 'Department of Rheumatology, \\ Tokyo Kyosai Hospital, Tokyo, Japan
}

\section{Key Words}

Anti-neutrophil cytoplasmic antibody · Sjögren's syndrome · Systemic sclerosis ·

ANCA-associated vasculitis

\begin{abstract}
A 65-year-old woman with a limited form of systematic sclerosis (SSc) and Sjögren's syndrome (SS) was admitted to our hospital for the evaluation of renal dysfunction. Her serum creatinine was $1.6 \mathrm{mg} / \mathrm{dl}$, proteinuria was $1.6 \mathrm{~g} /$ day, and the urine sediment contained 20-29 erythrocytes/high-power field. Myeloperoxidase anti-neutrophil cytoplasmic antibodies, antiSS-A/SS-B antibodies and anti-centromere antibodies were positive. A renal biopsy showed focal necrotizing glomerulonephritis with focal interstitial lymphoplasmacytic infiltration. A diagnosis of anti-neutrophil cytoplasmic antibody-associated vasculitis (AAV) was made. A steroid therapy was initiated and AAV subsided. This is a rare case of AAV in a patient with anti-centromere-positive limited SSC and SS.

(C) 2015 S. Karger AG, Basel
\end{abstract}

\section{Introduction}

Anti-neutrophil cytoplasmic antibody (ANCA) was first described by Davies et al. [1]. Since then, ANCA-positive vasculitis has come to be known as ANCA-associated vasculitis (AAV). ANCA-associated glomerulonephritis, which is characterized by ANCA positivity, ne-

KARGER 125/s $\quad \begin{aligned} & \text { Yoshifumi Ubara, MD } \\ & \text { Nephrology Center, Toranomon Hospital } \\ & \text { 2-2-2 Minato, Tokyo 105-8470 (Japan) } \\ & \text { E-Mail ubara@toranomon.gr.jp }\end{aligned}$




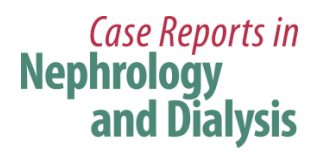

Case Rep Nephrol Dial 2015;5:113-117

\begin{tabular}{l|l}
\hline DOI: 10.1159/000381946 & $\begin{array}{l}\text { @ 2015 S. Karger AG, Basel } \\
\text { www.karger.com/cnd }\end{array}$ \\
\hline
\end{tabular}

Kubota et al.: ANCA-Associated Vasculitis in a Patient with Systematic Sclerosis and Sjögren's Syndrome: A Case Report

crotizing glomerulonephritis and rapidly progressive renal dysfunction, represents AAV with renal involvement. The classification of vasculitis was updated by the Second International Chapel Hill Consensus Conference in 2012, and it was proposed that vasculitis, accompanied by other autoimmune diseases, would be described by adding a term to specify the systemic disease (e.g., rheumatoid vasculitis, lupus vasculitis, etc.) [2].

ANCA-associated glomerulonephritis rarely occurs in patients with systemic sclerosis (SSc) [3, 4] or Sjögren's syndrome (SS) [5-7]. Here we report a Japanese woman who developed ANCA-associated glomerulonephritis at the age of 8 years after the diagnosis of both SSc and SS.

\section{Case Presentation}

In January 2013, a 65-year-old Japanese woman was admitted to our hospital for the evaluation of renal dysfunction. In 2005, when she was 56 years old, SS was diagnosed because of a positive Schirmer/Rose Bengal test and the detection of anti-SS-A antibody at a titer of 1:16. A limited form of SSc was also diagnosed at that time because of a thickening of the finger skin, Raynaud phenomenon, and positivity for anti-centromere antibody (titer of 1:167). Thereafter, she was followed up without any medication. In April 2012, serum creatinine was $1.0 \mathrm{mg} / \mathrm{dl}$ and urinalysis was normal.

On admission, the patient was $155 \mathrm{~cm}$ tall and weighed $48.2 \mathrm{~kg}$, with a blood pressure of $139 / 70 \mathrm{~mm} \mathrm{Hg}$ and a temperature of $36.5^{\circ} \mathrm{C}$. Her serum creatinine was $1.6 \mathrm{mg} / \mathrm{dl}$, proteinuria was $1.6 \mathrm{~g}$ daily, and the urine sediment contained 20-29 erythrocytes/high-power field. ANCA was measured by enzyme-linked immunosorbent assay. It was positive for myeloperoxidase (MPO) at 130 enzyme-linked immunosorbent assay units (EU)/ml (normal $<10 \mathrm{EU} / \mathrm{ml}$ ), but was negative for anti-proteinase-3 and anti-glomerular basement membrane (GBM) antibodies. Antinuclear antibody was positive at a titer of 1:1280, anticentromere antibody was positive at a titer of $167.0 \mathrm{U} / \mathrm{ml}$ (normal; <10.0), anti-SS-A antibody at a titer of 1:16, and anti-SS-B antibody was positive at a titer of 1:8. However, doublestranded-DNA, Smith, U1-nuclear ribonucleoprotein (RNP), RNA-polymerase III, rheumatoid factor, cyclic citrullinated peptide, and scleroderma (Scl)-70 antibodies were all negative.

Interstitial lung disease was noted by CT, but there was no neurological or skin involvement.

\section{Renal Biopsy}

A light microscopic examination of a renal biopsy specimen containing 23 glomeruli revealed a global or segmental sclerosis in 5 glomeruli and necrotizing glomerulonephritis with fibrin deposition in 2 glomeruli (fig. 1a, b), but definite crescent formation was not noted. Focal interstitial lymphoplasmacytic infiltration was also seen (fig. 1c). There was no edematous narrowing or obliteration of renal interlobular arteries and arterioles. Immunofluorescence microscopy did not demonstrate any deposits of immunoglobulin or complement, and there were no electron-dense deposits on electron microscopy. ANCA-related necrotizing glomerulonephritis and focal interstitial nephritis were diagnosed, and tubulointerstitial nephritis was considered to have a close association with SS. However, SScrelated small arterial lesions were not noted.

\section{Clinical Course}

Her treatment was initiated with intravenous methylprednisolone pulse therapy $(1,000$ $\mathrm{mg} /$ day for 3 days), followed by prednisolone (PSL) at $40 \mathrm{mg} /$ day. The MPO-ANCA titer be- 


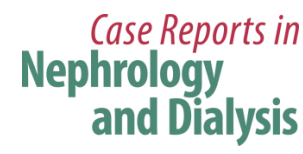

\begin{tabular}{l|l}
\hline \multicolumn{2}{l|}{ Case Rep Nephrol Dial 2015;5:113-117 } \\
\hline DOI: $10.1159 / 000381946$ & $\begin{array}{l}\text { C } 2015 \text { S. Karger AG, Basel } \\
\text { www.karger.com/cnd }\end{array}$ \\
\hline
\end{tabular}

Kubota et al.: ANCA-Associated Vasculitis in a Patient with Systematic Sclerosis and Sjögren's Syndrome: A Case Report

came normal within 6 months of starting treatment, and PSL was gradually tapered to $10 \mathrm{mg}$ daily. Proteinuria decreased to $0.3 \mathrm{~g}$ daily, but serum creatinine remained at $1.6 \mathrm{mg} / \mathrm{dl}$. One year after starting treatment, PSL was tapered to $5 \mathrm{mg}$ daily and azathioprine was added at $50 \mathrm{mg}$ daily. Urinalysis remained almost normal.

\section{Discussion}

In 2011, Arad et al. [3] reported 3 patients with the diffuse form of SSc and ANCAassociated renal vasculitis. All 3 patients were positive for antinuclear antibodies and Scl-70 antibodies as well as MPO-ANCA (or p-ANCA). In addition, cellular crescents were detected in the glomeruli along with fibrin deposits in 2 patients. They performed a retrospective review of the literature using the PubMed database and summarized the characteristics of 35 patients with SSc and AAV, revealing that 29 patients were positive for Scl-70 antibodies [3]. Derrett-Smith et al. [4] reported a patient with an overlap of U3RNP-positive diffuse cutaneous SSc and PR3-positive microscopic polyangiitis. A renal biopsy showed necrotizing glomerulonephritis and vasculitis involving the small arteries. They performed a cohort study using a research database of 2,200 SSc patients between 1999 and 2010 and obtained useful information on 9 out of 35 patients who fitted the criteria for both SSc and vasculitis. Among them, 7 patients had the diffuse form of SSc and 1 patient had the localized form. Scl70 was positive in 1 patient, while U1-RNP and U3-RNP were positive in 2 patients each. In addition, MPO-ANCA was positive in 7 patients and anti-proteinase- 3 was positive in 1 patient [4].

In 1992, Böttinger et al. [5] reported a 74-year-old woman with an initial diagnosis of SS who was positive for MPO-ANCA and had necrotizing and crescentic glomerulonephritis. Moreover, Hernández et al. [6] reported a patient with primary SS who developed crescentic glomerulonephritis associated with ANCA positivity. This patient was positive for the rheumatoid factor, antinuclear antibodies, anti-SS-A, anti-SS-B, and MPO-ANCA, while a renal biopsy showed cellular crescents in 16 out of 18 glomeruli. Kamachi et al. [7] reported a similar case in 1999. In 1998, Font et al. [8] reported that ANCA was positive in 9 out of 82 patients with SS. They found that anti-SS-A antibodies were positive in 5 patients, p-ANCA was positive in 7 patients, and C-ANCA was positive in 2 patients, but there was no renal involvement. According to Horak et al. [9], the most common renal manifestation in patients with SSc is renal crisis associated with edematous narrowing or obliteration of the interlobular arteries and arterioles, while it is focal tubulointerstitial nephritis in patients with SS. In contrast, glomerulonephritis is rare in both SSc and SS.

In this case, only monotherapy with a high dose of corticosteroids was started. ANCA positive glomerulonephritis has been treated with aggressive therapy that usually includes high-dose corticosteroids and cyclophosphamide [10]. While in scleroderma, the use of glucocorticoids, particularly in high doses ( $\geq 15 \mathrm{mg} /$ day of prednisone), and cyclosporine, a renal vasoconstrictor, have been warned to have a close association with an increased risk of scleroderma renal crisis [11], although scleroderma renal crisis is very rare in classic anticentromere-positive limited scleroderma.

In conclusion, we reported the rare case of MPO-ANCA-associated glomerulonephritis in a patient with both anti-centromere antibody-positive limited SSc and SS. 
Kubota et al.: ANCA-Associated Vasculitis in a Patient with Systematic Sclerosis and Sjögren's Syndrome: A Case Report

\section{Acknowledgments}

This study was funded by the Okinaka Memorial Institute for Medical Research.

\section{Disclosure Statement}

All authors report no conflicts of interest.

\section{References}

1 Davies DJ, Moran JE, Niall JF: Segmental necrotizing glomerulonephritis with antineutrophil antibody: possible arbovirus aetiology? Br Med J (Clin Res Ed) 1982;285:606-607.

-2 Jennette JC, Falk RJ, Bacon PA, et al: 2012 Revised International Chapel Hill Consensus Conference Nomenclature of Vasculitides. Arthritis Rheum 2013;65:1-11.

-3 Arad U, Balbir-Gurman A, Doenyas-Barak K, et al: Anti-neutrophil antibody associated vasculitis in systemic sclerosis. Semin Arthritis Rheum 2011;41:223-229.

4 Derrett-Smith EC, Nihtyanova SI, Harvey J, et al: Revisiting ANCA-associated vasculitis in systemic sclerosis: clinical, serological and immunogenetic factors. Rheumatology 2013;52:1824-1831.

5 Böttinger EP, Niles JL, Colins AB, et al: Antineutrophil cytoplasmic autoantibody-associated vasculitis presenting as Sjögren's syndrome. Arthritis Rheum 1992;35:1373-1376.

-6 Hernández JL, Rodrigo E, De Francisco AL, et al: ANCA-associated pauci-immune crescentic glomerulonephritis complicating Sjögren's syndrome. Nephrol Dial Transplant 1996;11:2313-2315.

7 Kamachi M, Migita K, Tominaga M, et al: Sjögren's syndrome complicated by MPO-ANCA positive crescentic glomerulonephritis. Nephrol Dial Transplant 1999;14:1033-1034.

8 Font J, Ramos-Casals M, Cervera R, et al: Antineutrophil cytoplasmic antibodies in primary Sjögren's syndrome: prevalence and clinical significance. Br J Rheumatol 1998;37:1287.

-9 Horak P, Smrzovaa A, Krejcia K, et al: Renal manifestations of rheumatic diseases. A review. Biomed Pap Med Fac Univ Palacky Olomouc Czech Repub 2013;157:98-104.

10 Falk RJ, Gross WL, Guillevin L, et al; American College of Rheumatology; American Society of Nephrology; European League Against Rheumatism: Granulomatosis with polyangiitis (Wegener's): an alternative name for Wegener's granulomatosis. Arthritis Rheum 2011;63:863-864.

-11 Steen VD, Medsger TA Jr: Case-control study of corticosteroids and other drugs that either precipitate or protect from the development of scleroderma renal crisis. Arthritis Rheum 1998;41:1613. 


\section{Case Reports in \\ Nephrology \\ and Dialysis}

\begin{tabular}{l|l}
\hline \multicolumn{2}{l}{ Case Rep Nephrol Dial 2015;5:113-117 } \\
\hline DOI: 10.1159/000381946 & $\begin{array}{l}\text { ○ 2015 S. Karger AG, Basel } \\
\text { www.karger.com/cnd }\end{array}$ \\
\hline
\end{tabular}

Kubota et al.: ANCA-Associated Vasculitis in a Patient with Systematic Sclerosis and Sjögren's Syndrome: A Case Report
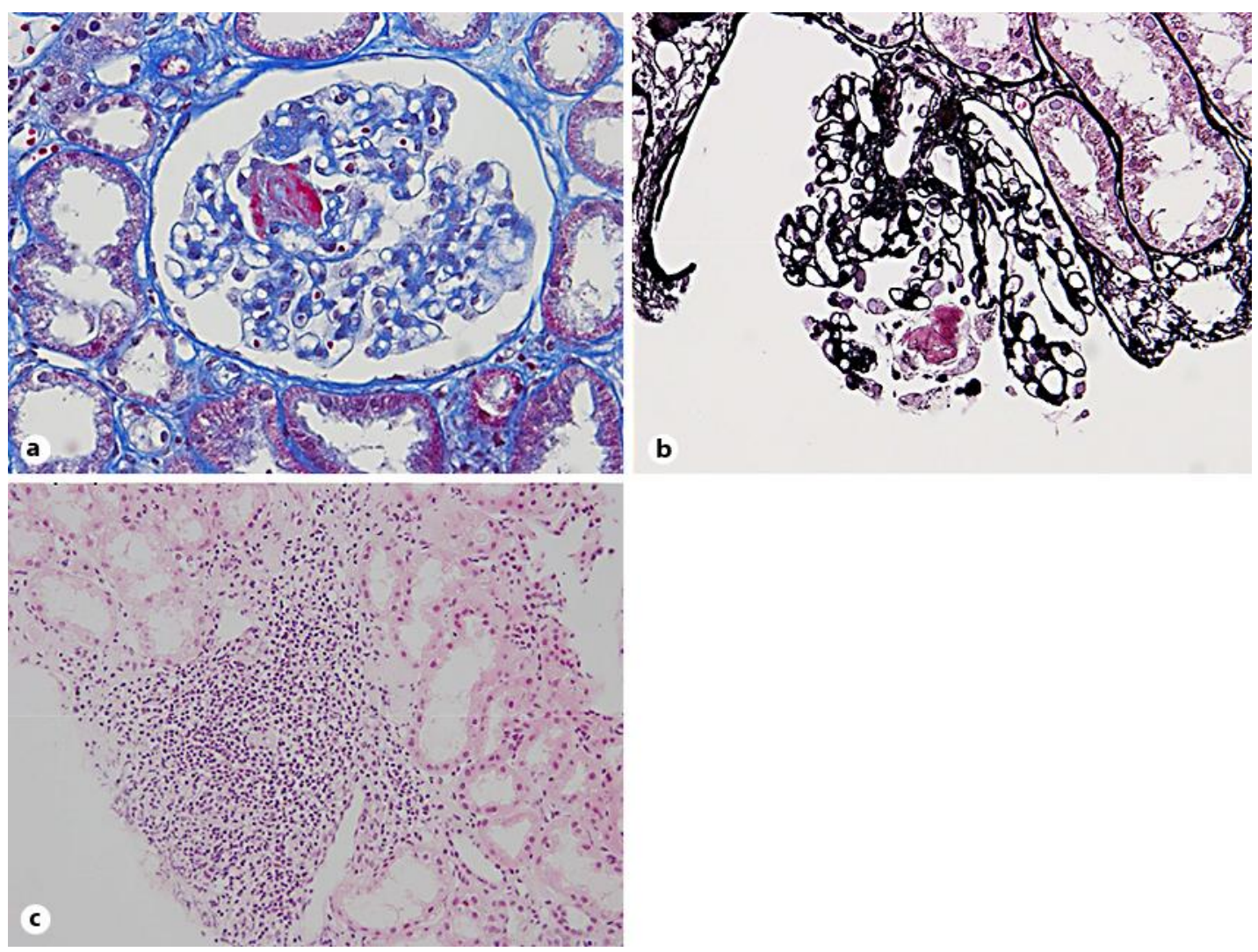

Fig. 1. Renal biopsy specimen. a, b Necrotizing glomerulopathy with fibrin deposition in 2 glomeruli. (a Masson trichrome stain; b Periodic acid-silver methenamine stain). c Focal interstitial lymphoplasmacytic infiltration. HE stain. 